\title{
SOLUÇÃO PARA IMPLANTAÇÃO DE SISTEMAS DE GERENCIAMENTO DE COMBUSTÍVEL*
}

Nayara Maron Costa Takahashi ${ }^{1}$

\section{Resumo}

Com o crescente aumento nos preços dos produtos derivados de petróleo no Brasil, o gerenciamento de combustível se torna cada vez mais relevante na tentativa de redução de custos operacionais da planta. Este aspecto envolve, além do controle do combustível movimentado, a detecção de desvios associados a perdas e furto, bem como análises de consumo e desempenho dos veículos e equipamentos abastecidos, e análises de eficiência dos próprios postos de combustível. Neste contexto, um Sistema de Gerenciamento de Combustível contempla a instrumentação necessária para a medição dos volumes transferidos e armazenados nos postos; o sistema de automação utilizado para o processamento, monitoramento e envio dos sinais; e o sistema de gestão de combustíveis. Este trabalho abrange a instrumentação aplicável aos processos de Recebimento, Armazenamento e Abastecimento nos postos de combustível, os tipos de sistemas de controle utilizados neste mercado e as funcionalidades de um sistema de gestão, apresentando uma solução em arquitetura WEB para este sistema.

Palavras-chave: Gestão de combustível; Medição de derivados de petróleo; Automatização do abastecimento; Sistema de gerenciamento de combustível.

\section{Abstract}

\section{A SOLUTION FOR FUEL MANAGEMENT SYSTEMS}

The rising prizes of petroleum derived products in Brazil increase the relevancy of fuel management systems, in order to reduce plant's operational costs. This include the control of fuel transfers, the detection of deviances related with loss or steals, as well as performance analysis, such as vehicle and equipment consumption and performance (e.g. consumption per hour or distance worked) and filling station efficiency (e.g. timing between operations). Therefore, a fuel management system covers the instrumentation, used to measure the amount of fuel transferred and stored, the automation system, used to process, monitor and send the process data, and the management system. This paper describes about the applied instrumentation in all stages of the fuel process, about the options of control systems used in this branch of market and about the functionalities of a management system, introducing a solution using WEB systems.

Keywords: Fuel management system; Petroleum measurement; Fuel automation.

Engenheira de Controle de Automação (UFMG), Pós-graduada em MBA em Automação Industrial (USP), Engenheira de Operações Plena, Lifecycle Solutions/ Instrumentação e Automação, Chemtech Serviços de Engenharia e Software, São Paulo, SP, Brasil. 


\section{INTRODUÇÃO}

\subsection{Motivação e Relevância}

O gerenciamento de combustível em sites industriais caracteriza um aspecto relevante no controle de custos e na análise de desvios relacionados ao consumo de combustível. Devido à grande quantidade de combustível movimentado na indústria, um pequeno desvio associado a perdas ou a furto, se não detectado e corrigido, pode resultar em grandes impactos financeiros para a empresa. No entanto, estes impactos somente podem ser evitados ou mensurados, avaliados e corrigidos através do monitoramento e gerenciamento das movimentações de combustível realizadas na planta industrial.

Além do controle de custo e análise de desvios, o monitoramento das operações de combustível viabiliza análises gerenciais dos postos, embasando tomadas de decisão. Uma das funções possíveis é a análise de consumo e desempenho dos equipamentos e veículos do pátio industrial. O monitoramento do consumo individual de combustível, por exemplo, quando associado ao tempo de operação do equipamento ou à distância percorrida pelo veículo entre abastecimentos, permite avaliar se o consumo atual do veículo corresponde com seu consumo específico e, com isso, prognosticar problemas de eficiência e avaliar a necessidade de manutenção preventiva ou corretiva. Pode-se avaliar ainda a produtividade dos postos de combustível, mensurando, por exemplo, o tempo gasto entre abastecimentos ou a taxa de utilização das pistas, dentre outras análises possíveis.

\subsection{Objetivo do Trabalho}

O objetivo deste trabalho é apresentar as questões relevantes subjacentes ao processo de combustível, quanto ao monitoramento, controle e gerenciamento das informações sobre transferências de combustível realizadas em uma planta industrial. Para isso, serão apresentadas as principais características do processo e os procedimentos operacionais típicos envolvidos em cada etapa. Em seguida, será apresentada a solução abordada neste trabalho para a implementação de um Sistema de Gerenciamento de Combustível, abrangendo aspectos de instrumentação e automação do processo, tecnologias para automatização do abastecimento, arquitetura de redes e sistemas de aplicação WEB.

\section{VISÃO GERAL DO PROCESSO}

O processo de combustível líquido pode ser dividido em três etapas, denominadas neste trabalho como "Recebimento", "Armazenamento" e "Abastecimento". A primeira etapa consiste na transferência de combustível para as instalações da planta industrial que ocorre, usualmente, através de vagões-tanque ou caminhõestanque. Esta transferência pode ser caracterizada como interna, quando o combustível recebido é da própria empresa, ou pode ser uma transferência de custódia, quando o combustível é adquirido de um fornecedor, passando a ser de responsabilidade da empresa no momento da transferência. Neste último caso, o combustível é entregue juntamente com a nota fiscal do fornecedor, contendo informações do volume entregue, composição e características do produto. Esta nota fiscal é utilizada posteriormente para o pagamento do combustível adquirido, o 
que caracteriza um ponto crítico do processo, uma vez que é usual (e recomendável) verificar se o volume recebido condiz com o valor indicado na nota.

A Figura 1 ilustra a etapa de processo de Recebimento, enfatizando os tipos de transferência mais comuns. Vale ressaltar que a entrega de combustível através de vagão-tanque geralmente ocorre com a locomotiva da própria empresa, de forma que a transferência de custódia é realizada nas instalações do fornecedor, enquanto que no recebimento por caminhão-tanque a transferência de custódia ocorre nas instalações da empresa.

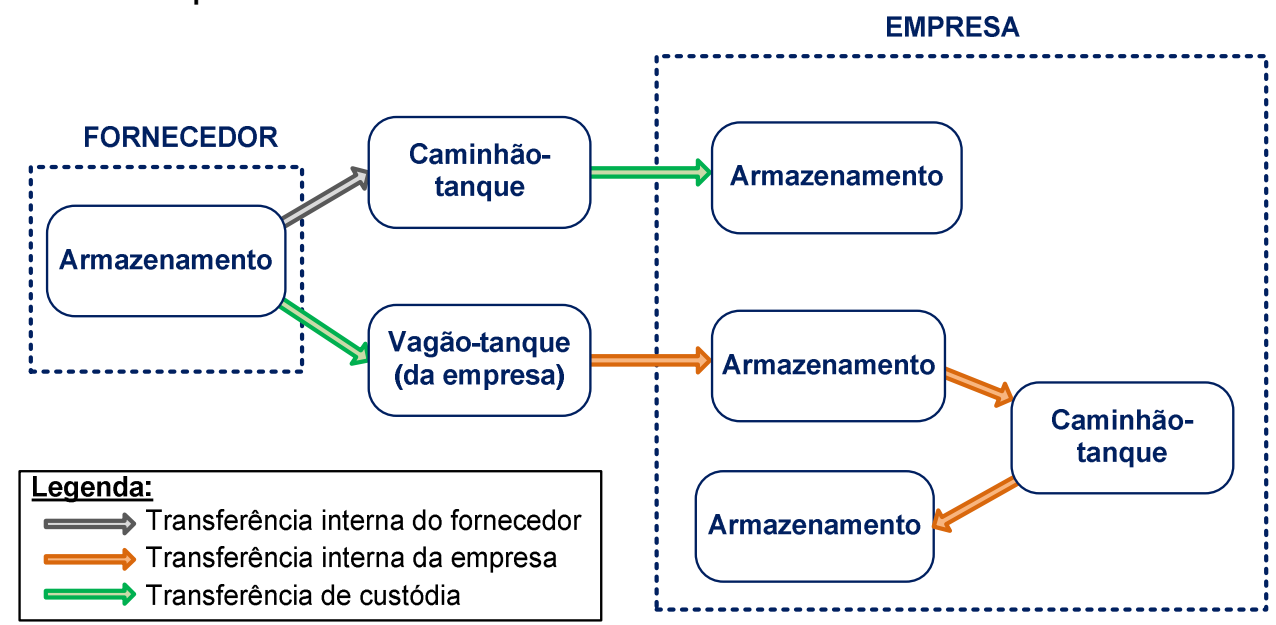

Figura 1. Representação do processo de Recebimento.

A etapa seguinte do processo consiste no armazenamento do combustível em tanques atmosféricos, superficiais ou subterrâneos. Para os postos de combustível onde há mais de um tanque para o mesmo tipo de fluido, estes compartilham a infraestrutura de tubulação, sendo necessárias válvulas de bloqueio para selecionar os tanques a serem carregados ou descarregados durante os processos de Recebimento e Abastecimento. A seleção dos tanques é realizada com base nos procedimentos operacionais do processo, que podem variar de acordo com o tipo das medições realizadas. Por exemplo, o volume de combustível recebido pode ser medido através de instrumentação na linha de entrada do processo ou inferido a partir da variação do nível no tanque de armazenamento. Neste último caso, a medição somente será possível se o tanque de destino estiver isolado, sendo que no caso de instrumentação em linha, o combustível pode ser descarregado em mais de um tanque sem afetar a medição do volume. A Figura 2 ilustra a etapa de processo de Armazenamento.

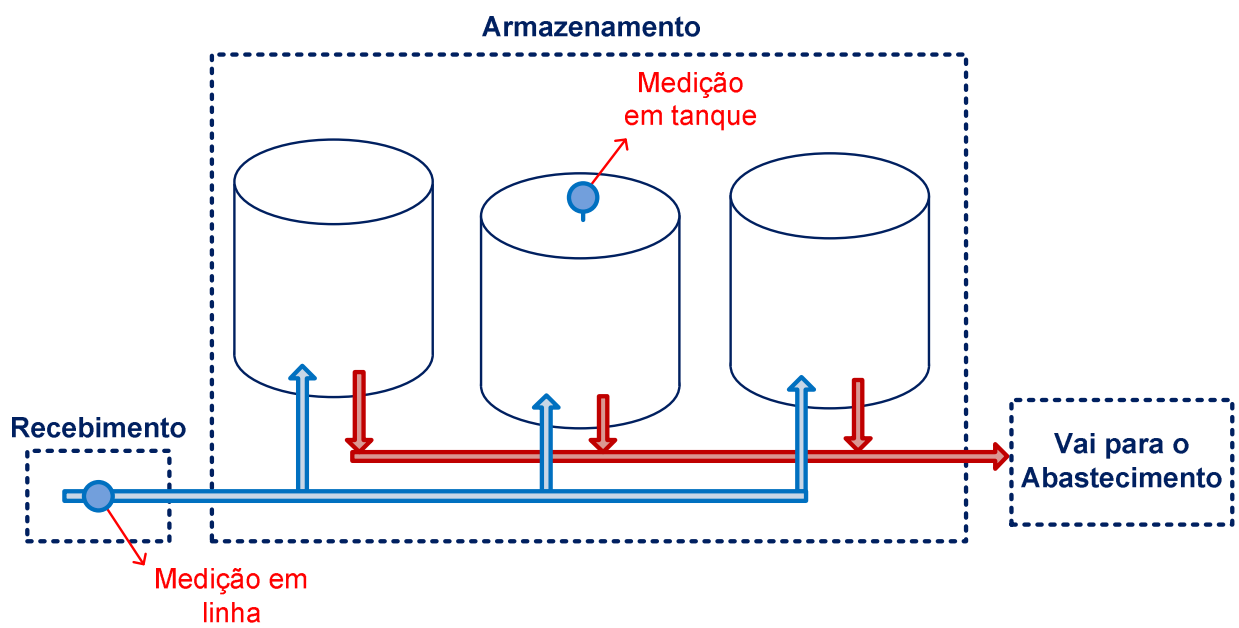

Figura 2. Representação do processo de Armazenamento. 
As características da infraestrutura e os procedimentos operacionais do Abastecimento dependem do tipo de veículo ou equipamento a ser abastecido. Nas plantas de mineração, por exemplo, são encontrados os seguintes tipos (Figura 3):

- Veículos leves: veículos utilizados para transporte de pessoas no interior da planta e caminhões de serviço de pequeno e médio porte;

- Veículos pesados: veículos operacionais de grande porte, como caminhões fora-de-estrada;

- Caminhão-tanque: caminhões utilizados para redistribuição de combustível a outros postos da própria empresa;

- Caminhões-comboio: caminhões com tanque e infraestrutura de abastecimento embarcada, sendo utilizados para o abastecimento de veículos ou de equipamentos fixos localizados na área operacional;

- Locomotivas: locomotivas utilizadas para o transporte de minério entre sites da empresa ou para o transporte de vagões-tanque.

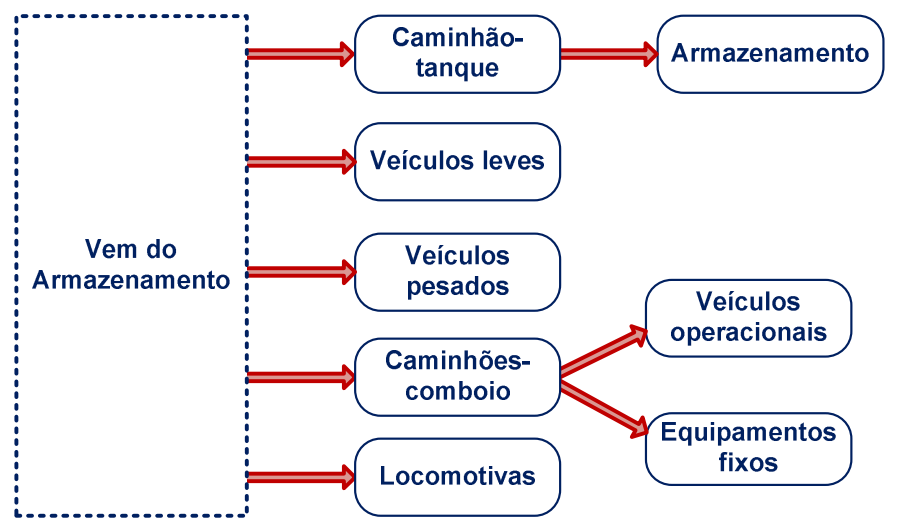

Figura 3. Representação do processo de Armazenamento.

A infraestrutura de abastecimento é composta por bombas, filtros de linha, bicos de abastecimento e instrumentos para medição do volume transferido, sendo adequada para cada aplicação. Os veículos leves e caminhões, usualmente, são abastecidos através de bombas medidoras com bico tipo gatilho, sendo o sistema de medição e de filtragem integrados à bomba. $O$ abastecimento de veículos pesados e locomotivas é realizado através de bombas, filtros e instrumentação instalados em linha, com bicos de engate rápido para alta vazão.

\section{SISTEMA DE GERENCIAMENTO DE COMBUSTÍVEL}

O gerenciamento de combustível envolve o registro e a análise de variáveis monitoradas no Recebimento, Armazenamento e Abastecimento, bem como o registro de informações relacionais, que em muitos casos não são obtidas automaticamente através de instrumentação de campo, mas são necessárias para a implementação do controle de inventário, cálculos de divergência, atribuição de custos do combustível movimentado e análises gerenciais. Os subitens deste capítulo discutem acerca das características gerais relevantes para um Sistema de Gerenciamento de Combustíveis em uma planta industrial, considerando a instrumentação necessária para a medição dos volumes transferidos e armazenados nos postos, o sistema de automação utilizado para o processamento, monitoramento e envio dos sinais, e o sistema de gestão de combustíveis. Vale ressaltar que os exemplos mencionados estão focados em plantas de mineração e movimentação de combustível líquido. 


\subsection{Instrumentação}

A instrumentação utilizada em um processo de combustível depende dos procedimentos operacionais do posto, de sua infraestrutura e dos acordos contratuais para a transferência de custódia do produto. A instrumentação típica utilizada para o monitoramento e controle do volume de combustível movimentado em cada etapa do processo é apresentada nos itens a seguir.

Vale ressaltar que os instrumentos aplicáveis ao processo não se limitam aos mencionados neste trabalho, uma vez que não se discute sobre os instrumentos e sistemas aplicáveis à segurança do processo [2], e sobre os instrumentos utilizados para avaliação da qualidade do combustível, por considerar que tais abordagens fogem ao escopo principal deste artigo.

\subsubsection{Etapa de recebimento}

Como mencionado na seção 2 , o volume recebido pode ser medido na linha de entrada do processo ou ser inferido pela diferença de nível no tanque. Para o caso de instrumentação em linha no Recebimento, diferencia-se entre:

- Transferência interna: o volume recebido é medido para fins de controle de inventário, cálculo da divergência e/ou análise de desvios (associado a vazamentos). Para este tipo de aplicação, utiliza-se um medidor de vazão/ volume em linha;

- Transferência de custódia: o volume medido é utilizado para comparação com o valor indicado na nota fiscal do produto. As diferenças detectadas podem ser apresentadas ao fornecedor para compensação (reclamação) do custo da nota fiscal ou complementação do volume faltante, desde que permitido no contrato de fornecimento entre as empresas. No caso de transferência de custódia são comumente utilizadas Estações de Medição (EMED) em formato de SKID, certificadas pela ANP/ Inmetro para este tipo de operação [1, 4].

Para as plantas de produção de petróleo, é obrigatória a correção da densidade e do volume medidos para a base de temperatura de $20^{\circ} \mathrm{C}[1,3]$, devido à variação de volume ocasionada pela variação da temperatura. Para postos consumidores, no entanto, a correção do volume é opcional, sendo a medição do volume realizada normalmente à temperatura ambiente. Assim, deve ser avaliada a aplicabilidade desta correção em cada planta industrial, a fim de padronizar a base de medição para temperatura padrão de $20^{\circ} \mathrm{C}$ ou para temperatura ambiente, considerando procedimentos operacionais da planta e o tipo de medição indicada na nota fiscal do fornecedor de combustível.

\subsubsection{Etapa de armazenamento}

A instrumentação utilizada nos tanques para a medição do volume armazenado depende da precisão requerida para esta medição e a finalidade da mesma. Dentre as possibilidades existentes, destacam-se:

- Medição básica: o volume armazenado é inferido a partir do sinal de um medidor de nível. O cálculo do volume é realizado com base na tabela de arqueação do tanque, fornecida pelo fabricante ou elaborada por um profissional qualificado. É importante ressaltar que o certificado de arqueação deve ser emitido pela Dimel (Diretoria de Metrologia Legal) do INMETRO ou por uma instituição por ela acreditada, para que o mesmo tenha validade legal; 
- Medição com compensação de temperatura: no caso de o padrão adotado para o posto de combustível ser a correção do volume medido à temperatura padrão de $20^{\circ} \mathrm{C}$, faz-se necessária a instalação de um medidor de temperatura no tanque, além do medidor de nível;

- Medição com correção do volume de água: no interior dos tanques de armazenamento de combustível há formação de água, a qual fica acumulada em um reservatório (ou copo) no fundo do tanque. Caso não ocorra a drenagem, o nível de água aumenta, ultrapassando o limite deste reservatório. Com isso, a fim de compensar a quantidade de água no tanque, são utilizados sensores de interface para corrigir o volume de combustível medido pelo sensor de nível.

Conforme já mencionado, a medição do volume de combustível no tanque pode ser utilizada para inferir o volume descarregado na transferência de custódia. Neste caso, todos os instrumentos do tanque relacionados à medição ou correção do volume devem ser certificados pela ANP/ Inmetro para este tipo de operação [1].

\subsubsection{Etapa de abastecimento}

As informações na etapa de Abastecimento são de grande relevância no gerenciamento do processo de combustível, pois, além das medições do volume transferido, faz-se necessária a coleta de dados do veículo para validar a liberação do abastecimento, atribuir os custos do consumo e registrar o histórico operacional dos veículos (valores de horímetro e odômetro). Para isso, a automatização de todo o processo de Abastecimento envolve diferentes tipos de instrumentos, dispositivos e tecnologias, a depender do tipo da informação requerida:

- Medição do volume transferido: o volume abastecido é medido para fins de controle de inventário e apropriação de custos, sendo a instrumentação de acordo com o tipo de veículo. Para veículos leves e caminhões rodoviários são utilizadas bombas medidoras, enquanto que para locomotivas e veículos pesados são utilizados medidores de vazão/ volume em linha, com bico de alta vazão. No caso de o padrão adotado para o posto de combustível ser a correção do volume medido à temperatura padrão de $20^{\circ} \mathrm{C}$, faz-se necessária também a instalação de um medidor de temperatura em linha;

- Dados do veículo ou equipamento: antes de iniciar o abastecimento se faz necessário identificar o veículo ou equipamento, a fim de atribuir o custo do combustível ao departamento ou à empresa responsável, bem como para validar a permissão do abastecimento. Atualmente existem diferentes tecnologias no mercado para a identificação automática do veículo e liberação automática do abastecimento, sendo a tecnologia RFID a mais utilizada no momento, por ser mais robusta e menos susceptível à fraude;

- Dados de horímetro/ odômetro: as informações de horímetro e odômetro são registradas a cada abastecimento, a fim de viabilizar análises de produtividade dos veículos e equipamentos pela equipe de gerência dos postos. Existem soluções no mercado que utilizam tecnologia para coletar automaticamente estas informações e enviar via wireless ao sistema de controle do posto. Outra solução utilizada é a inserção manual dessas informações em IHMs do sistema de gerenciamento de combustível, evitando a utilização de registros em formulários de papel. 


\subsection{Sistema de Automação}

Em um processo de combustível, o sistema de automação é determinado com base na instrumentação utilizada e na automatização requerida. Nas etapas de Recebimento e Armazenamento, as variáveis monitoradas se referem somente ao volume de combustível transferido, podendo ser aplicada ainda a correção da medição para a temperatura padrão de $20^{\circ} \mathrm{C}$. Na etapa de Abastecimento, dependendo do nível de automatização requerido, o sistema de controle deve ser adaptado para atender as diferentes fontes de informação. O monitoramento e/ou cálculo do volume transferido ocorre da mesma forma que nas demais etapas do processo, no entanto, os dados de horímetro/ odômetro e os dados de identificação do veículo, quando automatizados, necessitam de equipamentos específicos para integrar os instrumentos de campo com o sistema de controle. Alternativamente, quando se opta pela inserção manual dos dados relacionais em IHM do sistema de gerenciamento, faz-se necessário adequar a infraestrutura de rede do posto para a comunicação entre as IHMs e o sistema de gerenciamento.

A definição do sistema de controle depende ainda de uma avaliação quanto à implantação de sistemas abertos, através de CLPs, ou sistemas fechados, através de controladores proprietários. Existem no mercado diferentes sistemas dedicados (proprietários) principalmente para a etapa de Abastecimento, pelo fato desta etapa ser mais complexa que as demais, em termos de quantidade de informações relacionais. Estes sistemas são capazes de registrar os dados operacionais e processar funções de gestão de combustível, como liberação do abastecimento, controle de inventário e geração de relatórios.

A escolha do tipo de sistema de controle (aberto ou fechado) deve levar em consideração questões como:

- Compatibilidade de instrumentos: Em caso de sistemas de controle fechados, deve ser avaliado se os instrumentos se comunicam através de protocolo proprietário e se são, portanto, compatíveis com o controlador;

- Manutenção: Em caso de uso de CLPs, deve ser avaliada a disponibilidade de equipe de manutenção na planta para alterações no sistema, quando necessário. Em caso de sistemas fechados, geralmente é realizado um contrato de manutenção com o fornecedor, devendo ser avaliado o tempo de atendimento pela equipe técnica e as funcionalidades disponíveis no sistema para os casos de contingência (falha na instrumentação ou no sistema de controle);

- Armazenamento dos dados: Em caso de sistemas abertos, as informações coletadas podem ser armazenadas no sistema de aquisição de dados da planta ou, para os dados relacionais, diretamente no banco de dados do sistema de gerenciamento. Em caso de sistemas fechados, geralmente os dados são armazenados em memória local e enviados periodicamente ao sistema de gerenciamento, devendo ser, portanto, avaliada a autonomia do sistema para operar em modo offline, em caso de falha de comunicação com o sistema de gerenciamento.

\subsection{Sistema de Gerenciamento}

A gestão do processo de combustível envolve a análise sobre os volumes de combustível movimentados, para fins de controle de inventário, cálculo de divergência e atribuição de custos, bem como para gerar indicadores de 
desempenho do processo e/ou de equipamentos. Além das informações de processo, são registradas informações relacionais, utilizadas para liberação e para identificação dos abastecimentos.

Em sistemas fechados (proprietários) de controle de combustível, há soluções em que as funcionalidades de gerenciamento dos dados são disponibilizadas parcialmente no próprio sistema de controle, com a geração de relatórios e cálculos menos complexos. Nestes casos, as funcionalidades adicionais do sistema e a gestão das informações são realizadas pelo fornecedor, podendo ser contratadas como serviço adicional. Os dados são enviados ao Data Center do fornecedor e os resultados das análises (relatórios e gráficos) são enviados à equipe de gestão de combustíveis da planta. No entanto, deve ser avaliado o tipo de contrato de serviços, a fim de verificar a vantagem em adquirir este serviço, quando comparado à solução de implantação de um sistema de gerenciamento de combustível próprio da planta e interligação dos controladores (CLPs ou proprietários) a este sistema.

O presente trabalho apresenta uma solução aberta para a implantação de um sistema de gerenciamento de combustível. Propõe-se um sistema em arquitetura WEB, dado que o sistema de gerenciamento é utilizado nos diferentes níveis hierárquicos do processo, ou seja, desde a equipe de operação (frentistas) até a equipe de gestão dos postos e/ou da empresa. Nesta solução, cada site (posto ou conjunto de postos de combustível) possui um servidor de aplicação WEB e um banco de dados local, ambos interligados à rede de TA ou a rede DMZ da planta. Desta forma, qualquer usuário autorizado pode acessar a interface do sistema de gerenciamento via browser de internet, inserir dados relacionais, quando necessário, ou consultar os relatórios e gráficos disponíveis.

Para empresas compostas por diferentes sites, pode ser requerida a integração das informações de todos os postos de combustível em um mesmo sistema. Neste caso, considera-se a implantação de uma aplicação WEB integradora e de um banco de dados na camada da rede corporativa. Esta aplicação, no entanto, geralmente é utilizada para a visualização das informações (relatórios e gráficos gerenciais), não permitindo a inserção de dados operacionais, a fim de evitar conflitos em acessos simultâneos nos servidores de banco de dados locais e corporativo.

A Figura 4 apresenta a arquitetura de Automação para a implementação de um sistema de gerenciamento de combustível (SGC) através de arquitetura WEB.

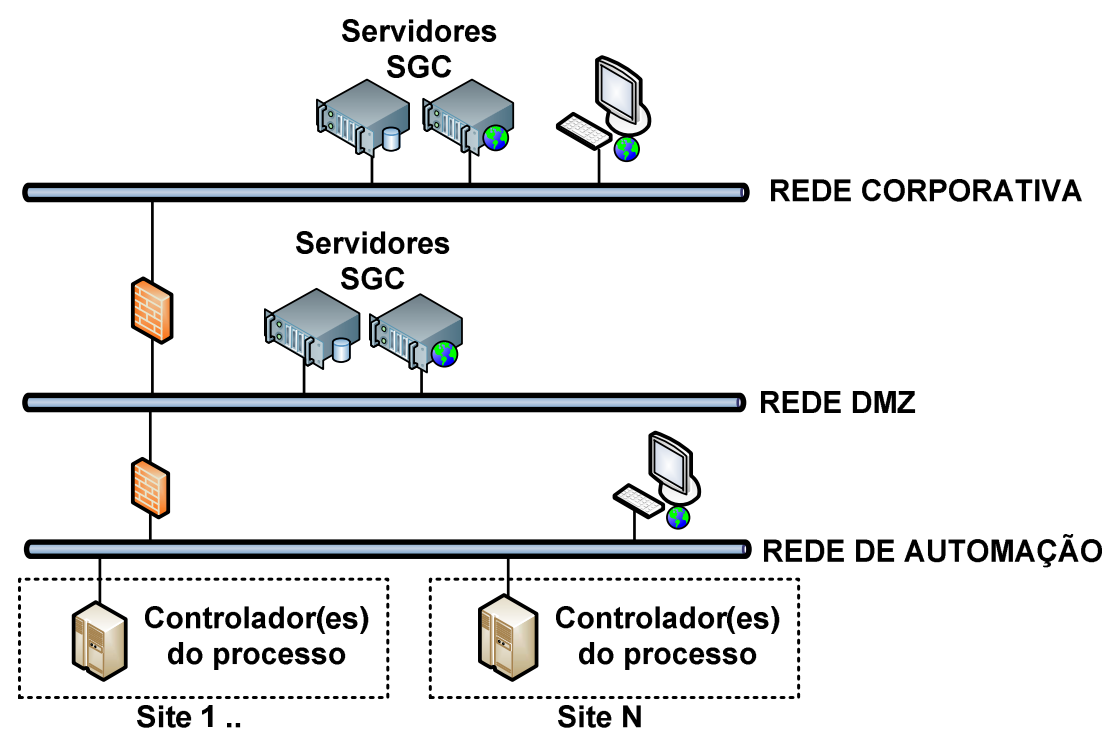

Figura 4. Arquitetura de Automação, com servidores do sistema de gerenciamento na rede DMZ e rede de corporativa. 


\section{CONCLUSÃO}

O gerenciamento de um processo de combustível envolve desde a instrumentação de campo, para a medição dos volumes movimentados, passando pelo sistema de automação, responsável pelo processamento dos sinais e os cálculos e correções dos volumes medidos, até o sistema de gestão, onde ocorrem análises de desempenho do processo e são implantados os procedimentos operacionais de cada site. Dentre os benefícios resultantes da implantação de um sistema de gerenciamento de combustíveis, destacam-se:

- Aumento da integridade dos dados, com a redução ou eliminação da entrada manual de informações;

- A operação se torna menos susceptível a fraudes, pois as informações inseridas no sistema são rastreáveis e o acesso aos dados se torna mais restrito e difícil de ser violado. Além disso, com a automatização do controle de inventário e cálculo da divergência, podem ser avaliados desvios no processo que indiquem a ocorrência de possíveis fraudes e desvios;

- Aumento da produtividade do efetivo dos postos e dos equipamentos, devido à redução de tarefas manuais e do tempo de permanência dos veículos no Abastecimento;

- Disponibilidade de ferramentas para análise de desempenho do processo (taxa de ocupação de pistas, abastecimentos por turno, etc.) e de equipamentos e veículos (consumo por abastecimento, consumo específico, etc.);

- Acesso remoto aos dados do processo de combustíveis, através de browser de internet, permitindo a visualização de relatórios e gráficos gerenciais, dentre outras.

Adicionalmente, este artigo propõe a instalação de um sistema de gerenciamento aberto, em arquitetura WEB, tornando possível a implantação de funcionalidades e interfaces customizadas para uso desde a operação (pelos frentistas) até a equipe de gestão. Nesta solução, podem ser interligados sistemas de controle abertos (CLPs) e/ou proprietários, desde que possuam capacidade de comunicação através de protocolo aberto.

\section{REFERÊNCIAS}

1 ANP/ Inmetro. Regulamento Técnico de Medição de Petróleo e Gás Natural. Resolução Conjunta ANP/INMETRO nำ 2013.

2 ABNT NBR 17505-2. Armazenamento de líquidos inflamáveis e combustíveis, Parte 2: Armazenamento em tanques, em vasos e em recipientes portáteis com capacidade superior a 3000 L. 2003.

3 CNP. Resolução CNP no6. "Aprova novas tabelas de coeficientes para correção de densidade e do volume dos derivados de petróleo". 1970.

4 Churro JJT. Evolução da normatização e do mercado de medição de petróleo e gás natural no Brasil. InTech 134. 2011; pág. 45 a 51. 